\title{
Nina Rodrigues e a Modernização Através da Ciência das Raças
}

\author{
Bruno Chies
}

\section{Resumo:}

O artigo discorre sobre as características modernas da obra de Nina Rodrigues, um importante representante de uma das vertentes do darwinismo racial e de um pensamento de época dominante em um país que buscava se modernizar. Mais do que expor a invalidez e as falácias de uma teoria científica, visamos explorar os modos pelos quais projetos de conhecimento e de poder estão intimamente ligados, no esforço de trazer questões ainda pertinentes e que possam ser relevantes para a compreensão de nossos processos de construção do conhecimento científico moderno.

Palavras-chave: Nina Rodrigues, raça, biopoder, modernidade, invenção. 


\section{Introdução}

Neste trabalho tentarei lançar uma determinada visão sobre o papel desempenhado pela medicina da época de Nina Rodrigues, tomando este autor tanto como figura representativa de um pensamento de época, quanto um dos mais expoentes inventores e arquitetos de um determinado tipo de saber, que traz consigo a sustentação e legitimação de certa autoridade. É interessante analisar seu pensamento com o foco direcionado mais para essa segunda chave de interpretação, sem desconsiderar, obviamente, a primeira, mas também sem cair na falácia de retratá-lo única e exclusivamente como mera circunstância de seu tempo. Contar a história do ponto de vista dos vencedores sempre é a opção mais fácil, o duro é saber localizar quais batalhas ainda estão sendo travadas, quais problemáticas ainda perduram. Nesse sentido, acredito que mesmo um breve recorte sobre o pensamento desse homem de ciência e de sua disciplina pode nos fornecer elementos para pensar o presente, apesar de sua relativa distância no tempo e da distância das premissas teóricas, que parece ser ainda maior. E como toda boa antropologia que se preze, proponho aqui esse exercício de diminuição da distância e do estranhamento (teórico, principalmente), para consequentemente podermos pintar outra imagem de nós mesmos, o que significa trazer o autor e algumas questões que ele nos coloca para os dias atuais.

O empreendimento científico de Nina Rodrigues também se tratava de um empreendimento político, que visava, junta a outras aspirações, instaurar a medicina como saber legítimo, que poderia ser utilizado como uma espécie de ferramenta, ou mesmo como fundamento lógico para guiar um projeto de nação e as políticas para colocar o país nos trilhos da modernização. Enquanto que a medicina social carioca de finais de século XIX tinha por área de atuação principalmente o meio urbano, com programas de higiene pública e concentração de esforços nos estudos das doenças tropicais, a medicina baiana (principalmente a partir dos anos I890) consagrou a chamada "escola Nina Rodrigues" como aquela que instaurou a medicina legal no Brasil. "Ou seja, enquanto para os médicos cariocas tratava-se de combater doenças, para os profissionais baianos era o doente, a população doente que estava em questão" (SCHWARCZ, I993, p.I90).

Para além dessas diferenças entre escolas e suas áreas de atuação, temos evidente que a medicina fundamenta sua especificidade enquanto conhecimento no corpo. Seja ele individual ou social, o que importa é criar mecanismos para ao mesmo tempo conhecê-lo e curá-lo, examiná-lo e intervir em sua saúde, afinal, "o corpo é uma realidade bio-política" (FOUCAULT, 200I, p.80). E é este objeto de estudo tão particular que confere à medicina a sua especificidade e sua capacidade de criar novas relações de poder. Basta lembrar a disputa que ela 
mantinha com o direito: a questão era olhar para o criminoso, e não, da maneira que o último pretendia operar, para o crime. Veremos isso detalhadamente na argumentação de Nina, mas por agora basta apontar que é na medicina que se procede o escrutínio do corpo, mas principalmente do corpo social, tomando o indivíduo como espécime de sua população, e descobrindo (criando) as diferentes biologias que compõem as diversas populações. Como veremos, o elemento chave na operação do conhecimento e do poder será a noção de raça e as negociações que se dão em cima desse termo. No entanto, vale a pena nos determos um pouco mais sobre como a medicina de época opera e instaura tecnologias de poder, que podem ser localizadas, de modo geral, na história do mundo ocidental (mais propriamente europeu). Segundo Foucault:

Temos portanto, desde o século XVIII (ou em todo o caso desde o fim do século XVIII), duas tecnologias de poder que são introduzidas com certa defasagem cronológica e que são sobrepostas. Uma técnica que é, pois, disciplinar: é centrada no corpo, produz efeitos individualizantes, manipula o corpo como foco de forças que é preciso tornar úteis e dóceis ao mesmo tempo. E de outro lado, temos uma tecnologia que, por sua vez, é centrada não no corpo, mas na vida; uma tecnologia que agrupa os efeitos de massas próprios de uma população, que procura controlar a série de eventos fortuitos que podem ocorrer numa massa viva; uma tecnologia que procura controlar (eventualmente modificar) a probabilidade desses eventos, em todo caso em compensar seus efeitos. [...] uma tecnologia que é mesmo, em ambos os casos, tecnologia do corpo, mas, num caso, trata-se de uma tecnologia em que o corpo é individualizado como organismo dotado de capacidades e, no outro, de uma tecnologia em que os corpos são recolocados nos processos biológicos de conjunto (FOUCAULT, 2002, p.297).

Enquanto que na Europa o desenvolvimento daquilo que Foucault chama de biopoder, como uma tecnologia articulada com e sobreposta ao poder de tipo disciplinar, irá ocorrer em fins do século XVIII, aqui no Brasil podemos observar esse movimento ocorrer mais na segunda metade do século XIX, se tomarmos a história da medicina como referência. No entanto, sabemos que esses diversos modelos foram incorporados aqui segundo as especificidades do pensamento brasileiro e de sua forma de interpretar uma realidade nacional. A principal dessas especificidades, como sabemos, é o papel que a noção de raça irá desempenhar nas articulações entre poder e saber, que na verdade irá atuar como principal dispositivo na realização desse biopoder. 
Tentarei expor a seguir como Nina Rodrigues foi capaz de ser um dos mais inventivos agenciadores do conceito de raça, colocando em prática essas distintas tecnologias de poder.

\section{A Raça Como Exercício de Poder}

Nina é um exemplo de autor que conseguiu levar até as mais longes consequências, conseguindo manter a coerência, todas as premissas teóricas darwinistas que orientavam o pensamento de época, darwinismo este que estava de fato em voga (SCHWARCZ, I993). O que caracteriza nosso autor como um pessimista em tempos pessimistas foi justamente sua habilidade em levar a sério a idéia de que, em um país onde a pureza de raças aparecia raramente, a miscigenação era um sinônimo de degeneração: física, psicológica, moral e consequentemente política.

Se falar na raça parecia oportuno - já que a questão referendava-se empiricamente e permitia certa naturalização de diferenças, sobretudo sociais -, o mesmo tema gerava paradoxos: implicava admitir a inexistência de futuro para uma nação de raças mistas como a nossa. Isto é, o conjunto dos modelos evolucionistas não só elogiava o progresso e a civilização como concluía que a mistura de raças heterogêneas era sempre um erro, e levava à degeneração não só do indivíduo como de toda a coletividade. (SGHWARCZ, I994, p.I38)

Estava na base do pensamento de Nina a idéia de que as raças configuravam realidades ontológicas, entidades homogêneas e bem delimitadas, que correspondiam a fases do processo evolutivo. A desigualdade e a diversidade de raças coexistentes poderiam ainda ser explicadas em termos evolutivos, nas palavras de Nina:

Não são tão simples e contingentes as causas do pé de desigualdade em que se apresentam na superfície do globo as diversas raças ou espécies humanas, que disputam sua posse. Ao contrário, ellas reproduzem no espaço, com mais ou menos fidelidade, os estadios ou phases, por que no tempo e sob a pressão de causas inexoráveis e poderosas, passou o aperfeiçoamento evolutivo daquelles grupos anthropologicos que conseguiram triumphar pela adaptação e occupar a vanguarda da evolução social.(RODRIGUES, I959, p.2I) 
A raça a qual Nina provavelmente se considerava pertencente, era aquela triunfante e a vanguarda da evolução social. Mais especialmente ainda, poderíamos dizer, a "raça" dos cientistas, daqueles que podem ter alguma ciência da natureza intrínseca ao homem ou às populações, era aquela que se resguardava o direito de legislar politicamente, sobre o crime por exemplo. É todo esse o argumento que perpassa sua obra As raças humanas e a responsabilidade penal no Brasil, onde ele alega que as raças superiores eram dotadas, devido a pressões evolutivas da seleção natural, das faculdades morais e intelectuais necessárias para julgar. Além disso, afirmava ele que a doutrina liberal presente no Código Penal (e aí tornase evidente o embate com os colegas do direito), que colocava todos os homens em pé de igualdade perante a lei, não passava de metafísica espiritualista, não sendo capaz de reconhecer os mais recentes fatos cientificamente estabelecidos a saber, o fato de que o indivíduo que comete o crime deve receber uma sanção de acordo com a sua localização biológica, com o grau de desenvolvimento moral e intelectual que sua natureza racial propicia. Em outras palavras, o criminoso é despojado de qualquer livre-arbítrio, seus atos são completamente determinados pela sua natureza (ou melhor, pela natureza de sua raça) e a criminalidade, portanto, é relativa a cada população e sua respectiva biologia.

Temos aí uma das manifestações mais evidentes do biopoder foucaultiano, daquele que inscreve determinadas propriedades no corpo social para ser capaz (ou poder, agora na qualidade de verbo) de intervir nele, sendo o conceito de raça o principal dispositivo dessa capacidade. Peco por citar novamente uma longa passagem de Foucault, mas que ilustra bem o ponto aqui desenvolvido:

No fundo, o evolucionismo, entendido num sentido lato - ou seja, não tanto a própria teoria de Darwin quanto o conjunto, o pacote de suas noções "como: hierarquia das espécies sobre a árvore comum da evolução, luta pela vida entre as espécies, seleção que elimina os menos adaptados" -, tornou-se, com toda a naturalidade, em alguns anos do século XIX, não simplesmente uma maneira de transcrever em termos biológicos o discurso político, não simplesmente uma maneira de ocultar um discurso político sob uma vestimenta científica, mas realmente uma maneira de pensar as relações da colonização, a necessidade das guerras, a criminalidade, os fenômenos da loucura e da doença mental, a história da sexualidade com suas diferentes classes, etc. (FOUCAULT, 2002, p.307, grifos nossos) 
Foucault segue mais adiante em seu texto discorrendo sobre a função do racismo nessas novas manifestações de tecnologias do poder, assumindo que ele se presta afinal ao direito de matar, direito de aniquilação do próprio corpo doente ${ }^{\mathrm{I}}$. Ora, no contexto europeu, quando nos referimos ao regime nazista, isso faz total sentido, mas e em contexto nacional? O racismo não pôde, felizmente, adquirir tais proporções, já que, se Brasil é praticamente sinônimo de miscigenação, tratar-seia então de auto-eliminação. É nesse sentido, por exemplo, que Giralda Seyferth afirma que a teoria do branqueamento de João Batista Lacerda se apresenta como "solução ideal e tipicamente brasileira para a questão racial" (SEYFERTH, I995), reflexo da preocupação de uma elite republicana com o problema da mestiçagem. Ou seja, sem dúvida é mais fácil aceitar a solução otimista de Lacerda, ainda nos conformes darwinistas, de sentar e esperar o mestiço branquear, do que pensar na possibilidade de um extermínio de praticamente toda a população brasileira.

Já com Nina, podemos esperar uma construção teórica que significa refinamento dessas técnicas de controle do mundo social-natural. Ainda como exemplo de sua vocação científica de classificação do mundo, o autor prossegue em seu ímpeto de controlar conceitualmente o mestiço, subdividindo-o em pelo menos três tipos. Pois o mestiço é o sujeito amorfo, heterogêneo, ou até mesmo o não-lugar, racialmente falando. Procedendo dessa forma, subdividindo e categorizando as raças e as não-raças (o lugar do mestiço degenerado), cumpre o cientista o seu papel político no exercício do biopoder. Temos assim, portanto, um primeiro mecanismo de exercício do saber-poder médico, que busca atuar também no aparelho jurídico e criminal, pensando e lidando com o contingente populacional por meio do dispositivo da raça. Tecnologia de poder muito interessante e peculiar que pode ser entendida como biopoder.

Um segundo aspecto digno de nota na obra de Nina Rodrigues, para ficarmos ainda com a terminologia foucaultiana, é a maneira pela qual os mecanismos de tipo disciplinar ainda se fazem presentes, e necessários, acima de tudo. Fazem parte de toda a metodologia de pesquisa de Nina e eles são melhor exemplificados nos estudos de caso em "Mestiçagem, degenerescência e crime". É a técnica disciplinar do exame (FOUCAULT, 200I) que constitui a base do texto e da análise de Nina, uma base para a construção de todo o seu saber médico sobre a amostra populacional da Serrinha e sobre as populações degeneradas de forma geral. É característico dessa técnica, em primeiro lugar, tornar o doente ou o sujeito pesquisado necessariamente visível, utilizar-se da observação até como uma

I "A morte do outro não é simplesmente a minha vida, na medida em que seria minha segurança pessoal; a morte da raça ruim, da raça inferior (ou do degenerado, anormal), é o que vai deixar a vida em geral mais sadia e mais pura" (FOUCAULT, 2002, p.305) 
forma ritualística de objetivação - a ciência como mais pura atividade empírica. Em segundo lugar, "o exame faz também a individualidade entrar num campo documentário" (Foucault, 200I, p.I57), e ao inserir o indivíduo em um campo documentário, transforma-o em "caso". É exatamente isso o que vemos o autor fazer nessa sua pesquisa, onde caso a caso insere o indivíduo em determinada população, buscando traçar suas origens, observando minuciosamente seu histórico de vida e estabelecendo todas as relações possíveis entre mestiçagem, degeneração e criminalidade. Ainda temos, não poderíamos esquecer, todo o aparato técnico no qual a medicina legal se apoia: frenologia, medição de crânios e outras métricas classificatórias que versam sobre a aparência física de cada exemplar da espécie. São todas técnicas particulares que no exame minucioso de cada corpo individual operam articuladas com a produção de conhecimento sobre o corpo social.

Ao nos debruçarmos sobre a obra de Nina Rodrigues, portanto, esta pode nos revelar um conhecimento, em seus próprios termos absolutamente verdadeiro e coerente, que organizava e classificava uma alteridade, a um só tempo dotando-a de sentido e estabelecendo relações de poder inéditas. E o conceito de raça, aliado às premissas evolucionistas, demonstrou ser um instrumento muito poderoso na conformação dessas novas tecnologias de poder-saber.

\section{A Sociedade-laboratório}

Tentei apresentar até o momento como o saber médico de Nina Rodrigues e sua época se configuraram também como novas formas de exercício de poder. Gostaria agora de seguir outra linha de argumentação, sugerindo olharmos para o empreendimento científico em si, que sustentou a criação dessa medicina ao mesmo tempo como uma prática de mundo e como um ideal ocidental que guiou essas práticas. Se compreendermos todo o trabalho de Nina e de seus contemporâneos como um projeto moderno, segundo a concepção que Bruno Latour nos apresenta em Jamais fomos modernos (I994), veremos que esses homens de sciencia estavam buscando entender uma realidade nacional em termos de suas características estáveis e determinadas pelo reino natural, de uma Natureza que se expressaria no comportamento e no modo de vida dos homens. Nada mais do que a Ciência como ferramenta de conhecimento por excelência para organizar de modo inteligível o caos da sociedade brasileira. É da seguinte maneira, portanto, que se terá uma imagem de Brasil, segundo Lilia Schwarcz aponta: 
E o fato é que o país representava, nesse sentido, um verdadeiro laboratório de raças; um recinto, onde poderiam se aplicar políticas, métodos, aparelhos de medição e teorias de inferioridade. (SCHWARCZ, 2009, comunicação pessoal)

A idéia da sociedade como um laboratório não é meramente uma metáfora ou uma alusão. Vale lembrar o valor que um laboratório assume para a atividade científica, um lugar que é condição de sua realização. Segundo Latour, é nele que se apresentam os fatos, é nesse recinto que se faz a comprovação daquilo que é inegável e que a Natureza simplesmente nos presenteia aos olhos. Isso caracteriza o seu caráter transcendental daquilo que se manifesta em laboratório, que ultrapassa e vai além de qualquer vontade e desígnio humano. No caso aqui tratado, são as raças de Nina Rodrigues, fatos da Natureza, que eliminam qualquer livre-arbítrio do indivíduo.

Por outro lado, temos inevitavelmente u m caráter imanente no laboratório. Ele é o lugar do controle, do planejamento, da maquinação de dispositivos, de todo o trabalho pesado que o cientista faz, tudo para que a Natureza e sua transcendência possam se revelar. Afinal, não é de graça que o homem teria algum tipo de acesso a esse reino, sem nenhum esforço, sem aquilo que Latour chama de trabalho de mediação. O trabalho de mediação caracteriza justamente aquilo que tratamos anteriormente, sobre as diversas técnicas de Nina.

O outro lado da Ciência ${ }^{2}$ enquanto ideal, digamos assim, é o trabalho de purificação, aquilo que seria o resultado e o intuito final da prática científica; separar aquilo que é do reino da Natureza daquilo que pertence ao reino dos homens, ou seja, a Cultura. E para adicionar ainda mais significado antropológico na atividade científica enquanto atividade de purificação, podemos concebê-la exatamente como uma espécie de ritual. Em Pureza e Perigo, de Mary Douglas, a autora demonstra que pares como sujeira e limpeza, puro e impuro, são categorias úteis para ordenar a vida social e para atribuir significado às coisas. Era essa mesma a intenção de nossa antiga elite de cientistas: aplicar essa série de rituais, visando purificar o país, manter a ordem, ao separar aquilo que é sujo daquilo que é puro. "Dirt offends against order. Eliminating is not a negative movement, but a positive effort to organize the environment" (DOUGLAS, I966, p.2). Como já vimos, a figura ameaçadora à ordem é o mestiço em especial. E justamente porque se concebia o país como um laboratório, era ali (aqui) mesmo que se fazia necessário intervir e realizar todo o trabalho de mediação. Encarando o país

2 A distinção entre "Ciência", letra maiúscula e no singular, e "ciências", minúscula e no plural, está em A Esperança de Pandora (LATOUR, 200I). A primeira refere-se mais ao valor, à idéia presente no projeto moderno, sobre o procedimento eficiente de separação entre Natureza e Cultura. A segunda refere-se ao conjunto de atividades práticas de mediação que em muito se difere da primeira. 
como um laboratório, os cientistas poderiam vislumbrar a meta da purificação na sociedade de amanhã. E, como vimos mais acima, eles criaram de fato diversas tecnologias de poder, na tentativa de reproduzir um ambiente controlado que é o laboratório.

Aqui também há um duplo jogo entre purificação e mediação: enquanto julgavam-se estar descobrindo verdades intrínsecas aos fenômenos que vivenciavam, no formato de raças e na forma de natureza(s) humana(s), estavam também produzindo verdades, produzindo fatos que circulariam naquele meio relativamente limitado (da elite pensante, diríamos?) e, acima de tudo, criando novas relações com o mundo, novas relações sociais ${ }^{3}$. Enfim, os homens de sciencia estavam também criando uma realidade nacional, através de suas atividades e de seus ideais, muito mais do que revelando sua natureza. O vocabulário aqui é muito mais o de significar do que o de descobrir. É nesse sentido que é interessante ver como a teoria de raças e o exercício científico tiveram esse caráter de invenção. É na atribuição de significado ao mundo, a partir de certas convenções simbólicas (como o darwinismo, por exemplo), que se inventa novas coisas. É isso que Roy Wagner argumenta (de forma muito mais elaborada, é claro) e desenvolve em seu The Invention of Culture, que em nosso caso aqui bem poderíamos tomar como inspiração para enxergarmos parodicamente um The Invention of Races.

Por fim, ainda é necessária uma última ressalva para que o argumento não seja mal interpretado. Como disse no começo, não devemos contar a história apenas do ponto de vista dos vencedores, reduzindo portanto os resultados científicos de época a mera ideologia, já que hoje é fácil constatar que raças não existem empiricamente e que o darwinismo social foi uma forma ultrapassada de teoria social que não foi capaz de dar conta de uma sociedade muito mais complexa do que se supunha. A teoria não estava dissonante da realidade, incorreta ou falsa. A teoria era, ela mesma, produtora de realidade, conformadora de uma situação social e instituidora de novas relações de poder antes inexistentes. A premissa ontológica se assemelha aí em muito àquela que Latour nos mostra em sua análise sobre Pasteur e seus micróbios (LATOUR, 200I): estes últimos simplesmente não existiam antes de todo o trabalho de mediação do primeiro. Da mesma forma devemos pensar as raças naturais classificadas por Nina e seus contemporâneos. Apesar da idéia de raça na espécie humana - tanto biologicamente, de maneira

3 Quando uso o termo "social" estou pensando imediatamente no sentido que Latour procura desenvolver em "Reassembling the Social" (2005), ou seja, não no sentido de uma substância, mas no sentido de uma série infinita de associações heterogêneas, produzidas por meio de diversos agenciamentos, inclusive aqueles entre humanos e não-humanos, que a própria atividade científica pode vir a criar. 
mais restrita, quanto em suas implicações conceituais sobre suas determinações sociais, psicológicas e cognitivas - estar hoje completamente refutada, na época ela existia factualmente e foi elemento central na produção de discursos e de relações de poder. Ainda assim, apesar de todas as negociações em cima da noção de raça e de sua atual invalidez no campo científico, ainda podemos observá-la sendo utilizada por diversos atores sociais, nas mais variadas formas de agenciamento ${ }^{4}$. Resquícios de tempo passado? De certa forma... Ressignificações? Sem dúvida! E, felizmente, existem várias delas no jogo político da atualidade, que extrapolam o âmbito do discurso científico. ${ }^{5}$

Talvez seja exatamente por isso que se faz necessário entender, como tópico antropológico e a partir de um olhar etnográfico, como essa noção de raça é ainda utilizada, que tipo de relações sociais ela sustenta e que outros tipos estão sendo instauradas/inventadas pelos atores a partir dela. São motivos suficientes para compreendermos que pensamentos e obras de autores como Nina Rodrigues, tão distantes, no tempo e teoricamente, não devam ser negligenciados.

\section{Referências Bibliográficas:}

FOUGAULT, Michel. Vigiar e Punir. Petrópolis: Vozes. 200I. O nascimento da medicina social, $O$ nascimento do hospital $e$ A política de saúde no século XVIII. In Microfísica do Poder. Rio de Janeiro: Graal. 200I.

Aula de I7 de março de I976. In Em defesa da sociedade: Curso no Collège de France (I975-I976). São Paulo: Martins Fontes. 2002.

DOUGLAS, Mary. Purity and Danger. London: Routledge and Kegan Paul, I966.

LATOUR, Bruno. Jamais Fomos Modernos: Ensaio de antropologia simétrica. Rio de Janeiro: Ed. 34, I994. - A Esperança de Pandora. Bauru: Edusc, $200 \mathrm{I}$.

4 É curioso também notar o quanto ainda perdura internacionalmente esta imagem construída do país. Ainda enquanto escrevia este trabalho, deparei-me com no uma entrevista no Estadão (oI de agosto de 2009) com um intelectual francês, Edgar Morin, que pensava o Brasil se destacando em termos de sua miscigenação, pluralidade étnica e biodiversidade.

5 Nunca se percebe que o seu discurso está em profunda ressonância (seja discordando ou concordando) com o discurso dos movimentos sociais. Estudos de raça e gênero são os exemplos mais representativos dessa afirmação que agora me ocorrem à cabeça. 
RODRIGUES, Nina. As raças humanas e a responsabilidade penal no Brasil. Bahia, Progresso (I ${ }^{\mathrm{a}}$ ed. I933), I959.

. Métissage, dégénérescence et crime. In: Archives d'anthropolqgie criminelle. Lion, I899.

SCHWARCZ, Lilia Moritz. O espetáculo das raças. Gientistas, instituições e questão racial no Brasil. I870-I930. São Paulo: Cia. das Letras, I993. . Espetáculo da miscigenação. Estud. av. São Paulo, v. 8, n. 20, Apr. 1994. Disponível em <http://www.scielo.br/scielo.php?script=sci_ arttext\&pid=SoI03-40I4I994000I000I7\&lng=en\&nrm=iso $>$

SEYFERTH, Giralda. A antropologia e a teoria do branqueamento da raça no Brasil, a tese de João batista de Lacerda. In: Revista do Museu Paulista, I985.

WAGNER, Roy. The Invention of Culture. Chicago: The University of Chicago Press, I98I [1975].

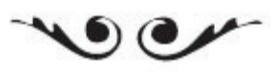

Bruno Chies é graduado em Ciências Sociais pela USP.

E-mail:xmeiou@gmail.com 